\title{
Mass Spectrometric Methods for Distinguishing Structural Isomers of Glutathione Conjugates of Estrone and Estradiol*
}

\author{
Ragulan Ramanathan \\ Department of Chemistry, Washington University, St. Louis, Missouri, USA \\ Kai Cao and Ercole Cavalieri \\ Eppley Institute for Research in Cancer and Allied Diseases, University of Nebraska Medical Center, Omaha, \\ Nebraska, USA
}

Michael L. Gross

Department of Chemistry, Washington University, St. Louis, Missouri, USA

Collisionally activated decompositions (CAD) of $[\mathrm{M}+\mathrm{H}]^{+}$ions from two sets (estrone and estradiol) of three isomeric glutathione (GSH) conjugates were studied by using five tandem mass spectrometric methods: (1) low energy (LE) CAD in an ion trap, (2) LE CAD in a triple quadrupole, (3) electrospray ionization (ESI)-source CAD in a tandem four sector, (4) high energy (HE) CAD of both ESI-produced and fast-atom bombardment (FAB)-produced ions in a tandem four-sector mass spectrometer, and (5) metastable-ion decompositions of FABproduced ions. Four types of fragment ions are produced. The first type, formed from cleavage of the peptide backbone, gives rise to modified $b_{2}$, modified $y_{2}, y_{2}$, and $b_{1}$ ions. These fragments are observed with all the methods and show that the catechol estrogen attachment is at the cysteine moiety of the GSH. Internal fragment ions are the second type, and they also support that the modification is at cysteine. The third type involves fragmentation of the C-S bond to give an ion containing the steroid bonded to the sulfur. The fourth type of fragment ion is similar to the third but involves oxidation of the steroid ring and reduction of the GSH moiety; it is the most isomer specific of the four. The isomer-specific ions are of relatively low abundance in the product-ion spectra taken on the triple quadrupole and ion trap, but their abundances can be improved by increasing the collision energy. ESI source-CAD and the HE-CAD spectra of the isomers are the most distinctive because abundant product ions of all four types are seen in a single spectrum. (J Am Soc Mass Spectrom 1998, 9, 612-619) (c) 1998 American Society for Mass Spectrometry

$\mathrm{E}$ ndogenous steroid hormones, estrone $\left(\mathrm{E}_{1}\right)$ and $17 \beta$-estradiol $\left(\mathrm{E}_{2}\right)$, are metabolized via two major pathways: 2- and 4-hydroxylation to form catechol estrogens (CE) and 16 $\alpha$-hydroxylation [1,2]. The CE metabolites are usually methylated by catechol-Omethyltransferases (COMT) or conjugated to form glucuronides and sulfates. All these pathways serve to prevent oxidation of $\mathrm{CE}$ to reactive electrophilic quinones. When the level of $\mathrm{CE}$ is elevated and/or the activity of conjugating enzymes is decreased, CE accumulate and can be further oxidized by peroxidases or cytochrome P450 to form CE quinones. The quinones

Address reprint requests to Dr. Michael L. Gross, Department of Chemistry, Washington University, One Brookings Drive, Box 1134, St. Louis, MO 63130. E-mail: mgross@wuchem.wustl.edu

*Presented in part at the 45th ASMS Conference, Palm Springs, CA, June 1997. are electrophilic and are susceptible to adduction, via Michael addition, to the nucleophilic groups of cellular macromolecules [3-5] and glutathione (GSH) [6]. Binding of $\mathrm{CE}$ quinones to DNA can lead to carcinogenesis [5], whereas binding to GSH leads to excretion [6].

Adduction to the tripeptide glutathione ( $\gamma$-glutamylL-cystenylglycine), which occurs in all living cells [6], and most abundantly in the liver cells, is one of the major excretory pathways for many structurally diverse substrates ranging from xenobiotics [7] to toxic metals [8]. In most cells, the GSH concentration is in the range of 0.1 to $10 \mathrm{mM}$, and the body maintains the ratio between the oxidized (GS-SG) and the reduced (GSH) forms as low as 0.1 [9], facilitating the conjugation of the reduced GSH by glutathione-S-transferases (GST) to exogenous and endogenous electrophiles [10].

Conjugation to GSH and adduction to DNA involve 
similar chemistry. Because adduct formation is a required early step in tumor initiation, the detection and characterization of estrogen-DNA adducts in target tissues is important for understanding carcinogenesis and for estimating risk. But detection and characterization of an estrogen-DNA adduct are difficult because only one base in $10^{6}-10^{8}$ is modified. On the other hand, quinones readily react with GSH to give more abundant and easily measured adducts. Mass spectrometry, in combination with tandem mass spectrometry, has been used to determine a variety of GSH conjugates [11-14], including those from in vitro and in vivo experiments [15]; a preliminary announcement of this work was made [16].

In the research reported in this article, we have taken the challenge of determining isomeric GSH adducts of estrone and estradiol. We compare the results from four tandem mass spectrometric methods in which MS/MS experiments only were conducted and from ESI-source CAD. The outcome of the first two methods is an LE-CAD spectrum of product ions from ESI-produced $[\mathrm{M}+\mathrm{H}]^{+}$ions; the product ions were formed in either an ion trap (method 1) or a triple-quadrupole mass spectrometer (method 2). Method 3 gives ESI-source CAD spectra, and method 4 produces an HE CAD spectrum of either ESI or FAB-produced ions; methods 3 and 4 utilize a tandem four-sector mass spectrometer. The outcome of method 5 is a metastable-ion (MI) spectrum from the four-sector instrument. The focus of the article is the evaluation of mass spectrometric methods for distinguishing structural isomers of catechol estrogen-GSH (CE-GSH) conjugates; we chose not to evaluate other analytical issues (limits of detection and quantification, linearity of calibration, etc.) even though we were able to obtain product-ion spectra, in some cases, of femtomole quantities of adducts.

\section{Experimental}

\section{Materials}

The conjugates were prepared by mixing the corresponding quinones in acetonitrile with a 50/50 water/ acetic acid solution of GSH [17]. UV, NMR, exact-mass measurements, and tandem mass spectrometry (MS/ MS) were used to confirm the structures of the GSH conjugates of estrone and estradiol. Synthesis and confirmation of these conjugates were described in a separate article [17].

\section{Mass Spectrometry}

The first set of LE-CAD spectra were acquired by using a Finnigan (Finnigan MAT, San Jose, CA, USA) quadrupole ion trap (LCQ) equipped with a Finnigan ESI source. Samples were dissolved in 50/49/1 methanol/ water/acetic acid to give a final concentration of 5 $\mathrm{pmol} / \mu \mathrm{L}$ and were introduced via a $5-\mu \mathrm{L}$ loop injector into a $10-\mu \mathrm{L} / \mathrm{min}$ flow of $50 / 49 / 1$ methanol/water/ acetic acid. Although the detection limit for modified GSH conjugates was approximately $25 \mathrm{fmol}$, a higher concentration was used to insure that the tandem mass spectra had a good signal-to-noise ratio. The spray needle was held at $4.2 \mathrm{kV}$, and $4.8 \times 10^{5} \mathrm{~Pa}$ coaxial flow of nitrogen was used to stabilize the spray. A heated $\left(200{ }^{\circ} \mathrm{C}\right)$ stainless steel capillary held at $5 \mathrm{~V}$ served as a counter electrode. Helium was introduced to a pressure of 1 mtorr for improving the trapping efficiency of the ion trap (background pressure of $2.7 \times 10^{-3} \mathrm{~Pa}$ ) and for use as the collision gas during the CAD event. Ions were detected by a $15-\mathrm{kV}$ conversion dynode interfaced to a channeltron electron multiplier.

The second set of LE-CAD experiments was carried out with a Finnigan TSQ 7000 triple quadrupole mass spectrometer, which was equipped with a Finnigan ESI source similar to that of the LCQ. The electrospray needle was held at $5000 \mathrm{~V}$, and the counter electrode, a heated stainless steel capillary, was held at $5 \mathrm{~V}$. Samples were dissolved in 50/49/1 methanol/water/acetic acid to give a final concentration of $50 \mathrm{pmol} / \mu \mathrm{L}$ and were loop injected into a $5-\mu \mathrm{L} / \mathrm{min}$ flow of the same solvent. The detection limit for steroid-modified GSH with the triple quadrupole is in the range of 5 to $50 \mathrm{fmol}$, but a higher concentration was used so that high quality tandem mass spectra could be obtained. For all MS/MS experiments, argon was used as collision gas at a pressure of approximately $0.33 \mathrm{~Pa}$. For obtaining the breakdown graphs, the collision energy was varied from 20 to $60 \mathrm{eV}$ by changing the offset voltage of Q2 with respect to that of Q1. For comparison of production spectra, a collision energy of $25 \mathrm{eV}$ was chosen.

ESI source-CAD, HE-CAD, and MI spectra of product ions were obtained by using a VG ZAB-T (Manchester, UK) four-sector tandem mass spectrometer [18] equipped with a VG ESI source. The ESI needle was at $8000 \mathrm{~V}$ and the counter electrode ("pepper pot") at 5000 $\mathrm{V}$. To induce CAD in the high-pressure region between the sampling cone and the skimmer, the sampling cone potential was increased to approximately $135 \mathrm{~V}$ above the optimal operating potential of $4177 \mathrm{~V}$. Skimmer lens, skimmer, ring electrode, and hexapole were typically held at $4125,4120,4115$, and $4115 \mathrm{~V}$, respectively. Nitrogen was used as bath and nebulizer gas with a flow rate of 400 and $12 \mathrm{~L} / \mathrm{h}$, respectively. Samples (50 $\mathrm{pmol} / \mu \mathrm{L})$, dissolved in 50/49/1 methanol/water/acetic acid, were injected into the flow of a similar solvent system via a six port Rheodyne 7125 injector with a 20- $\mu \mathrm{L}$ external loop. A Harvard model 22 syringe pump was used to infuse the solvent at a flow rate of 10 $\mu \mathrm{L} / \mathrm{min}$.

For FAB, samples were dissolved in 50/50 water/ methanol to give a final concentration of $2 \mathrm{nmol} / \mu \mathrm{L}$. A $1-\mu \mathrm{L}$ aliquot was loaded on the probe along with $1 \mu \mathrm{L}$ of glycerol with $1 \%$ trifluroacetic acid (GLY/TFA). A $\mathrm{Cs}^{+}$ion gun operated at $30 \mathrm{kV}$ was used to desorb the ions, which were accelerated to $+8.0 \mathrm{keV}$.

HE CAD mass spectra of ESI-produced ions were obtained after precursor-ion activation in the third 
field-free region (between MS1 and MS2). Sufficient helium was added to the collision cell, which was floated at $2 \mathrm{kV}$, to attenuate the ion beam by $80 \%$. The first (MS1) and second-stage (MS2) mass spectrometers were operated at resolving powers of 1000 and 800 (full width at half-height definition), respectively. To obtain high-energy CAD spectra of FAB-produced ions, the collision cell was floated at $4 \mathrm{kV}$, and sufficient helium was introduced into the cell to attenuate the ion beam by $50 \%$. Ten to fifteen 15 -s scans were signal-averaged for each spectrum. The metastable-ion decompositions of FAB-produced ions were followed under the same conditions as the HE CAD experiments, but no collision gas was introduced into the collision cell. All MI and CAD spectra were acquired by using a VG (Manchester, UK) data system equipped with a DEC Alpha 3000 work station, OPUS V 3.1X software, and a VG SIOS I interface.

\section{Nomenclature}

When referring to both $E_{1}$ and $E_{2}$ catechols, we will use the term CE. The terms $\mathrm{E}_{1}-\mathrm{GSH}$ and $\mathrm{E}_{2}-\mathrm{GSH}$ are used to refer to all isomers of estrone and estradiol, respectively. The nomenclature proposed by Roepstorff and Fohlman, as modified by Biemann [19], was used to describe the peptide backbone fragmentation of the GSH moiety. All GSH fragment ions containing catechol estrogen moiety, $\mathrm{R}_{x}$, are referred to as modified
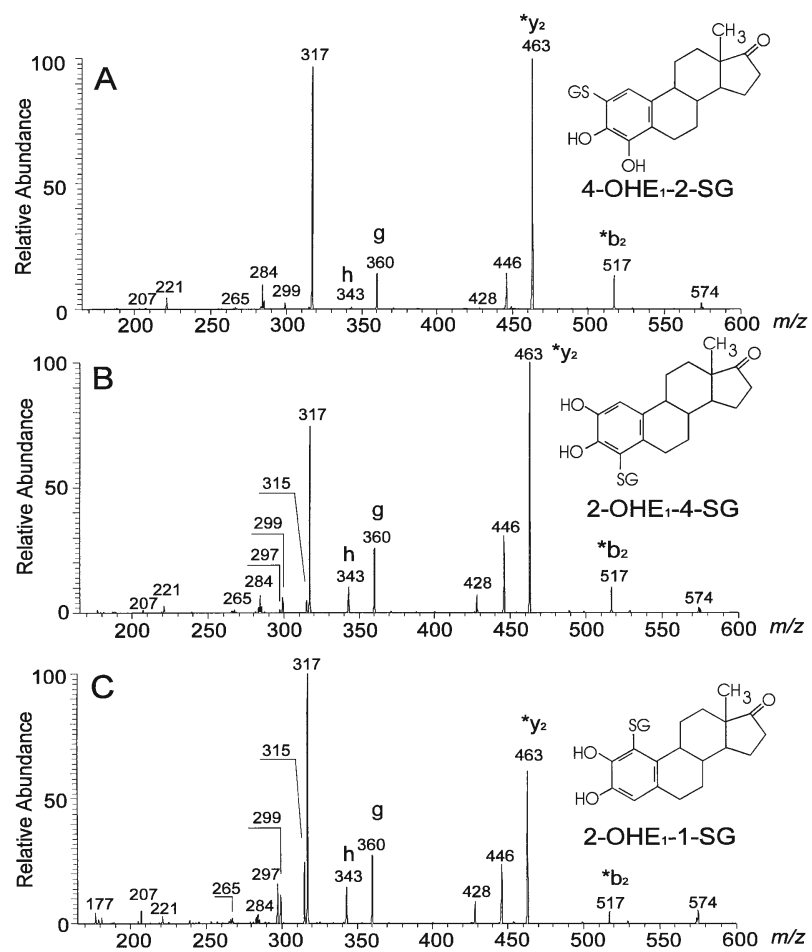

Figure 1. Tandem mass spectra of ESI-produced $[\mathrm{M}+\mathrm{H}]^{+}$ions from (A) 4-OHE $-2-\mathrm{SG}$, (B) 2-OHE 1 -4-SG, and (C) 2-OHE 1 -1-SG, obtained by using an ion-trap mass spectrometer.
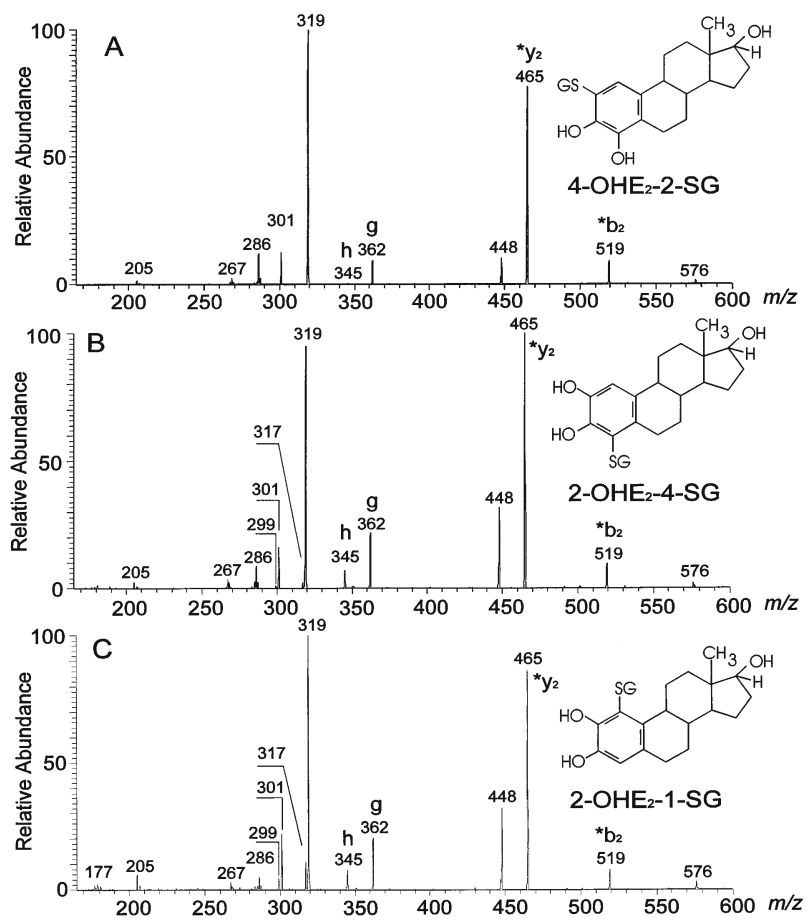

Figure 2. Tandem mass spectra of ESI-produced $[\mathrm{M}+\mathrm{H}]^{+}$ions from (A) 4-OHE $2-2-\mathrm{SG},(\mathbf{B}) 2-\mathrm{OHE}_{2}-4-\mathrm{SG}$, and (C) 2-OHE $2-1-\mathrm{SG}$, obtained by using an ion-trap mass spectrometer.

backbone fragment ions. Internal fragment ions are described by the nomenclature of Gaskell and coworkers [20].

\section{Results and Discussion}

In this study, we evaluate the effectiveness of five tandem mass spectrometric methods to characterize two sets of isomeric CE-modified GSH conjugates. One set consists of three isomers of estrone conjugates, and the second is represented by three isomers of estradiol conjugates (see Figures 1 and 2 for structures and abbreviations).

\section{Low-Energy CAD Spectra of ESI-Produced Ions on an Ion Trap}

To establish a reference point, we discuss briefly the LE CAD of GSH ( $\gamma$-glu-cys-gly) itself. ESI of GSH gives $[\mathrm{M}+\mathrm{H}]^{+}$and $[\mathrm{M}+\mathrm{Na}]^{+}$ions of $\mathrm{m} / z 308$ and 330, respectively. LE CAD of the $[\mathrm{M}+\mathrm{H}]^{+}$ions gives the expected $\mathrm{z}_{2}, \mathrm{y}_{2}$, and $\mathrm{b}_{2}$ ions of $m / z 162,179$, and 233.

LE CAD product-ion spectra of the $[\mathrm{M}+\mathrm{H}]^{+}$ions $\left(m / z\right.$ 592) of catechol $\mathrm{E}_{1}$-GSH conjugates $4-\mathrm{OHE}_{1}-2-\mathrm{SG}$, $2-\mathrm{OHE}_{1}-4-\mathrm{SG}$, and $2-\mathrm{OHE}_{1}-1-\mathrm{SG}$ are nearly identical (Figure 1). Similarly, the product-ion spectra of catechol- $\mathrm{E}_{2}-\mathrm{GSH}[\mathrm{M}+\mathrm{H}]^{+}$ions of $m / z 594$ from $4-\mathrm{OHE}_{2}-2-$ $\mathrm{SG}, 2-\mathrm{OHE}_{2}-4-\mathrm{SG}$, and 2-OHE $-1-\mathrm{SG}$ are also very similar (Figure 2). Peptide backbone fragmentations give rise to modified $b_{2}$, and $y_{2}$ ions, which we designate as 


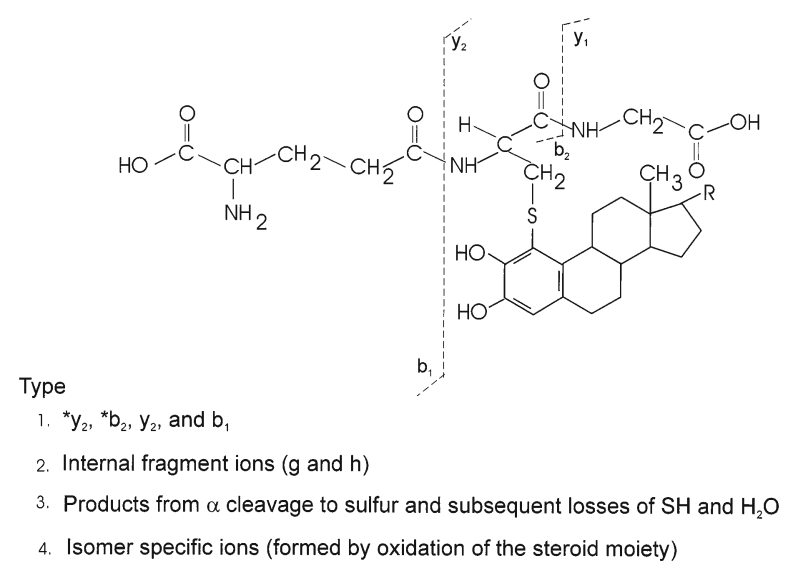

Scheme I. Four types of fragment ions observed with CE-GSH conjugates.

${ }^{*} b_{2}$ and ${ }^{*} y_{2}$, suggesting that the Cys moiety has been modified. We will refer to these and other product ions from backbone cleavages as "type 1" (see Scheme I). For $\mathrm{E}_{1}$ and $\mathrm{E}_{2}$ adducts, these fragment ions are at $m / z 517$ and 463 (Figure 1) and 519 and 465 (Figure 2), respectively, and are consistent with those reported in earlier studies of the LE CAD of GSH adducts [11-14]. Because there is a low-mass cutoff for the ion trap, the complementary $b_{1}$ and $y_{1}$ fragment ions could not be observed.

Internal fragment ions of the structure ${ }^{+} \mathrm{NH}_{2}=$ $\mathrm{CHCH}_{2} \mathrm{~S}-\mathrm{R}_{x}$ (Schemes I and II), where $\mathrm{R}_{x}$, is either the estrone or estradiol moiety are at $m / z 360$ (Figure 1) and 362 (Figure 2). These fragment ions are common in tandem mass spectra of GSH conjugates and are referred to as $g$ ions, following the nomenclature proposed by Gaskell and co-workers [20]. The same group also suggested that the $h$ fragment, ${ }^{+} \mathrm{CH}=\mathrm{CH}-\mathrm{S}-\mathrm{R}_{x}$, is formed by loss of ammonia from the $g$ fragment ion. For the purpose of organizing this article, we will call these ions "type 2."

For both sets of conjugates, the fragment ion of $\mathrm{m} / \mathrm{z}$ $317\left(E_{1}\right)$ or $319\left(E_{2}\right)$ from the cleavage of the C-S bond is the dominant product ion (Schemes I and III). This

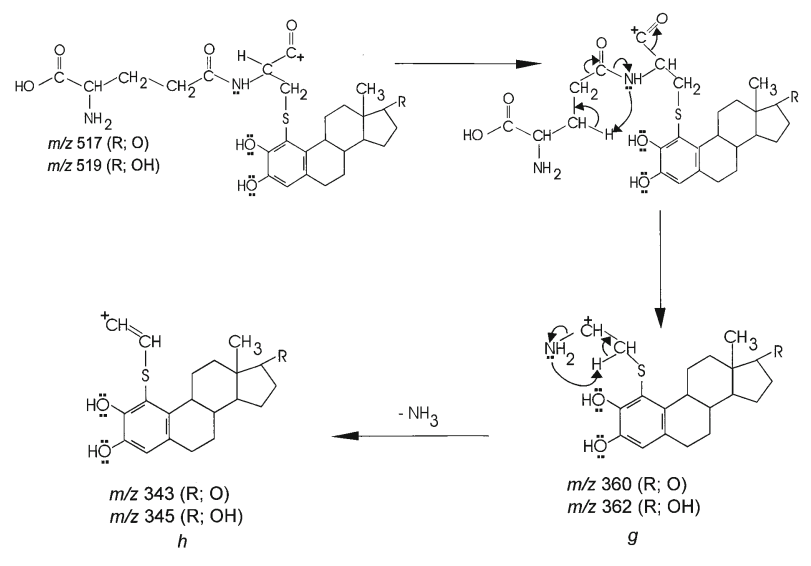

Scheme II. Proposed mechanism for formation of internal fragment ions.

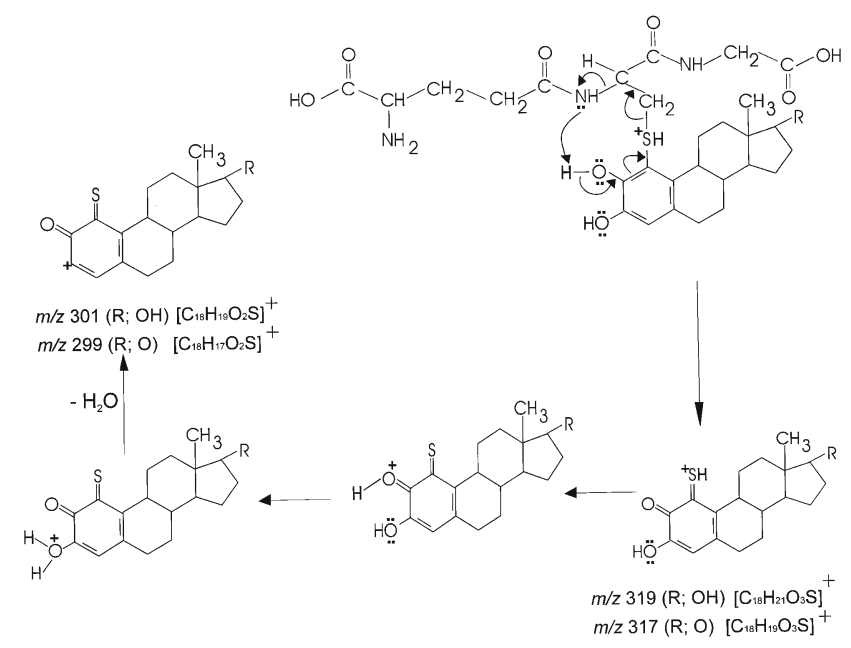

Scheme III. Proposed mechanism for formation of ion of $\mathrm{m} / \mathrm{z} 317$ and 299 and 319 and 301 from GSH conjugates of $E_{1}$ and $E_{2}$, respectively.

fragmentation releases the steroid as an ion with the sulfur attached. The $m / z 317$ and 319 ions subsequently lose $\mathrm{H}_{2} \mathrm{O}$ to give the product ions of $m / z 299$ or 301, respectively. These and the ions discussed next will be called "type 3."

The product ion of $m / z 284$ from $\mathrm{E}_{1}$-GSH conjugates and 286 from $E_{2}-G S H$ conjugates is likely to result from loss of an HS radical from the ions of $m / z 317$ or 319, respectively. This loss of HS is analogous to that from alkyl phenyl thioethers [21]. Loss of $\mathrm{H}_{2} \mathrm{~S}$ from GSH adducts was also observed previously [22] and may account for the low-abundance product ions of $m / z 283$ and 285 from the $m / z 317\left(E_{1}\right)$ and $319\left(E_{2}\right)$ ions, respectively.

An interesting pair of ions are those of $\mathrm{m} / \mathrm{z} 315$ and 297 from the $E_{1}-$ GSH conjugates and 317 and 299 from the $\mathrm{E}_{2}-\mathrm{GSH}$ conjugates; we will refer to these as "type 4." These product ions are not detectable when the GSH is attached at position 2 of the A ring of the steroid, barely detectable when the attachment is at position 4, and definitely detectable when the attachment is at position 1. Although neither fragment is of high abundance in the ion-trap, product-ion spectra, they assume considerably more importance in ESI-source CAD and HE CAD spectra, which will be discussed later.

Although the ion-trap spectra strongly suggest that Cys is modified by the steroid, the inability to observe $\mathrm{b}_{1}, \mathrm{y}_{1}$ in an MS/MS experiment and the relatively low abundances of the $y_{2}$ and type- 4 fragment ions make the identification of isomeric GSH conjugates difficult when using only one stage of MS/MS.

\section{CAD of ESI-Produced Ions in a Triple Quadrupole}

To evaluate triple quadrupole mass spectrometers for distinguishing these structural isomers and to assess if there is additional information for distinguishing isomers in the lower mass region of the tandem mass 


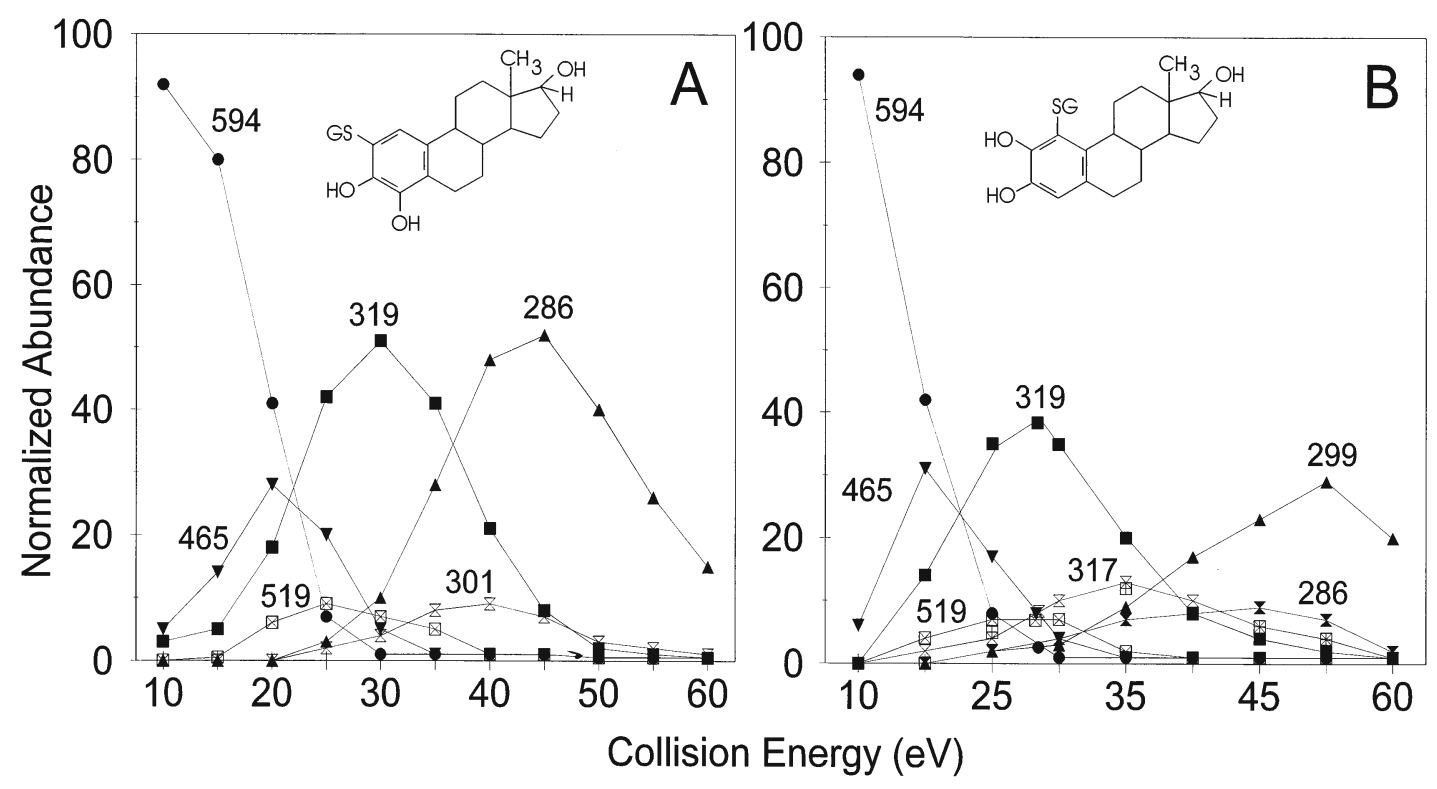

Figure 3. Breakdown graph of ESI-produced $[\mathrm{M}+\mathrm{H}]^{+}$ions from (A) 4-OHE ${ }_{2}-2-\mathrm{SG}$ and (B) 2-OHE ${ }^{-}$ 1-SG, obtained using a triple-quadrupole mass spectrometer.

spectra, we investigated the same set of conjugates with this instrumentation.

Energy-resolved CAD spectra. Energy-resolved spectra were obtained by systematically varying the collision energy and obtaining product-ion abundances as a function of that energy. Breakdown graphs for 4-OHE $\mathrm{H}_{2}$ 2-SG (Figure 3A) and 2-OHE $-1-\mathrm{SG}$ (Figure 3B) show that the ${ }^{*} \mathrm{y}_{2}$ of $m / z 465$ and the $m / z 519$ and 319 ions are primary fragments. With increasing collision energy in the range of $10-45 \mathrm{eV}$, the ion of $m / z 465$ fragments in part to form the ion of $m / z$ 319. Increasing the collision energy above $35 \mathrm{eV}$ causes the abundances of the isomer-specific fragment ions $(m / z 317,299$, and 286) and the low-mass fragment ions from the GSH moiety $(m / z 130,179,177,205$, and 207) to grow at the expense of the higher mass-to-charge ratio $(>345)$ fragment ions (some of these fragments are not shown in the figure to minimize congestion). The breakdown graphs clearly show isomeric differences; for 2-OHE $-1-\mathrm{SG}$, the $\mathrm{m} / \mathrm{z}$ 317 and 299 (type-4 ions) become the important secondand third-generation products, whereas they are not detectable for 4-OHE 2 -2-SG.

The breakdown graphs clearly show that the choice of collision energy is critical for distinguishing the spectra of the isomers. Because the four types of fragment ions can be seen at $25 \mathrm{eV}$, we chose that energy to compare tandem mass spectra of the six isomers.

LE CAD of CE-GSH adducts. At 25-eV collision energy, both sets of three isomers fragment most readily by $C-S$ bond cleavage (spectra not given). The peptide-backbone fragmentation gives the ${ }^{*} \mathrm{y}_{2}$ and ${ }^{*} \mathrm{~b}_{2}$ fragment ions at $m / z 517$ and 463, respectively. The type-2 product ions of $m / z \quad 360$ and 343, which are ${ }^{+} \mathrm{NH}_{2}=$
$\mathrm{CHCH}_{2} \mathrm{~S}-\mathrm{R}_{x}$ and ${ }^{+} \mathrm{CH}=\mathrm{CH}-\mathrm{S}-\mathrm{R}_{x}$, respectively, are relatively less abundant in the spectrum of $4-\mathrm{OHE}_{1}-2-\mathrm{SG}$, than in the spectra of the other two isomers. This trend also follows that obtained when using the ion trap.

The product ions of $m / z 317$ ( $\mathrm{E}_{1}$ adducts) or $319\left(\mathrm{E}_{2}\right.$ adducts) are most abundant. Differences pertain for the $\mathrm{m} / \mathrm{z} 315$ ion, which is absent in the spectrum of $4-\mathrm{OHE}_{1}-2-\mathrm{SG}$, of modest abundance in that of $2-\mathrm{OHE}_{1}-$ $4-\mathrm{SG}$, and relatively more abundant in that of $2-\mathrm{OHE}_{1}-$ 1-SG. The fragment ion of $m / z 297$, formed from loss of a water molecule from the ion of $m / z 315$, is absent in the spectra of $4-\mathrm{OHE}_{1}-2-\mathrm{SG}$ and present at modest and high abundance in the spectra of $2-\mathrm{OHE}_{1}-4-\mathrm{SG}$ and 2-OHE $-1-\mathrm{SG}$, respectively. An analogous situation applies to the $m / z 317$ and 299 ion from the $E_{2}$ isomers. These two pairs of product ions (i.e., of $m / z 315 / 297$ and $317 / 299$ ) are most important for distinguishing isomers.

Fragment ions of $m / z 284$ formed by loss of an HS radical from the $m / z 317$ ion, are also isomer specific. They are readily detectable from $4-\mathrm{OHE}_{1}-2-\mathrm{SG}$, modestly abundant from 2-OHE 1 -4-SG, and barely detectable from 2-OHE $-1-\mathrm{SG}$, an order that is opposite those for the $m / z 315$ and 297 ions. The corresponding fragments for the estradiol conjugates shift upward by $2 \mathrm{u}$, but the trends for dissociation are similar to those for the $E_{1}$ conjugates. Although we do not understand the reason for these trends, we note that the breakdown curves (Figure 3) show that the $m / z 286$ ion is the important terminal fragment for $4-\mathrm{OHE}_{2}-2-\mathrm{SG}$, whereas the $m / z 299$ ion plays the same role for $2-\mathrm{OHE}_{2}-1-\mathrm{SG}$.

Some low-mass fragment ions are also useful for distinguishing the isomers, but it is difficult to rationalize the trends. The unmodified $b_{1}$ ion of $m / z 130$ is one example (it is likely that this ion is a fragment of ${ }^{*} b_{1}$ ). 

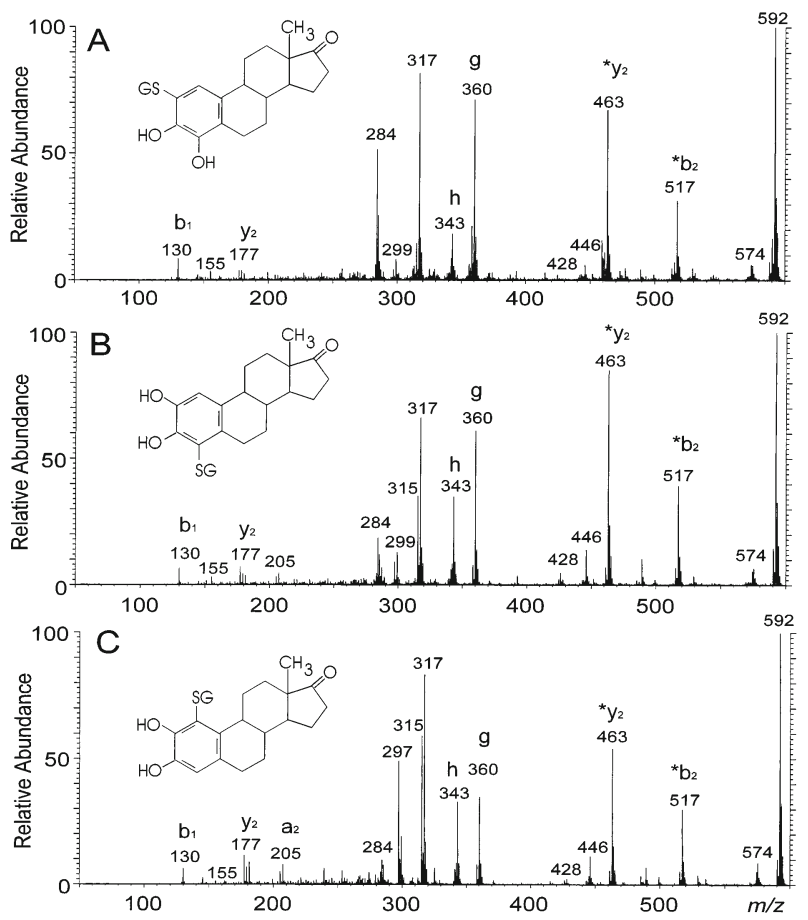

Figure 4. ESI-source CAD of ions from (A) 4-OHE $-2-\mathrm{SG}$, (B) 2-OHE $-4-\mathrm{SG}$, and (C) 2-OHE $-1-\mathrm{SG}$, obtained by using a tandem four-sector mass spectrometer.

Loss of $129 \mathrm{u}$ from GSH conjugates is one process that has been used in constant-neutral loss scanning to detect GSH conjugates from in vivo experiments [15].

Although establishing the expected attachment of CE to Cys is relatively simple using low-mass product ions, assigning a spectrum to a specific isomer is difficult. Results with the triple quadrupole, which are similar to those obtained with the ion trap, provide some evidence to distinguish the isomers. For example, although the fragment ions of $m / z 315 / 317$ and 297/299 are not clear evidence in the $25-\mathrm{eV}$ spectra of 2-CE-4-SG, increasing the collision energy enhances the abundance of these fragments but at the expense of the high-mass fragments. Clearly an integrated view of the energydependent fragmentation is needed to distinguish the isomers because no single LE CAD can provide a complete identification. The breakdown curves serve that function, but they require time and sample to generate. These limitations of LE CAD spectra prompted us to study these adducts by using ESIsource CAD and HE CAD on a tandem four-sector mass spectrometer.

\section{ESI-Source CAD in a Sector Mass Spectrometer}

Although ESI-source CAD requires introduction of pure samples into the mass spectrometer, it can have, when conducted on a magnetic sector mass spectrometer, relatively high-mass resolving power. ESI of $\mathrm{E}_{1}$ conjugates yields dominant $[\mathrm{M}+\mathrm{H}]^{+}(m / z 592)$ and negligible $[\mathrm{M}+\mathrm{Na}]^{+}\left(m / z\right.$ 614). Similarly, ESI of $\mathrm{E}_{2}$

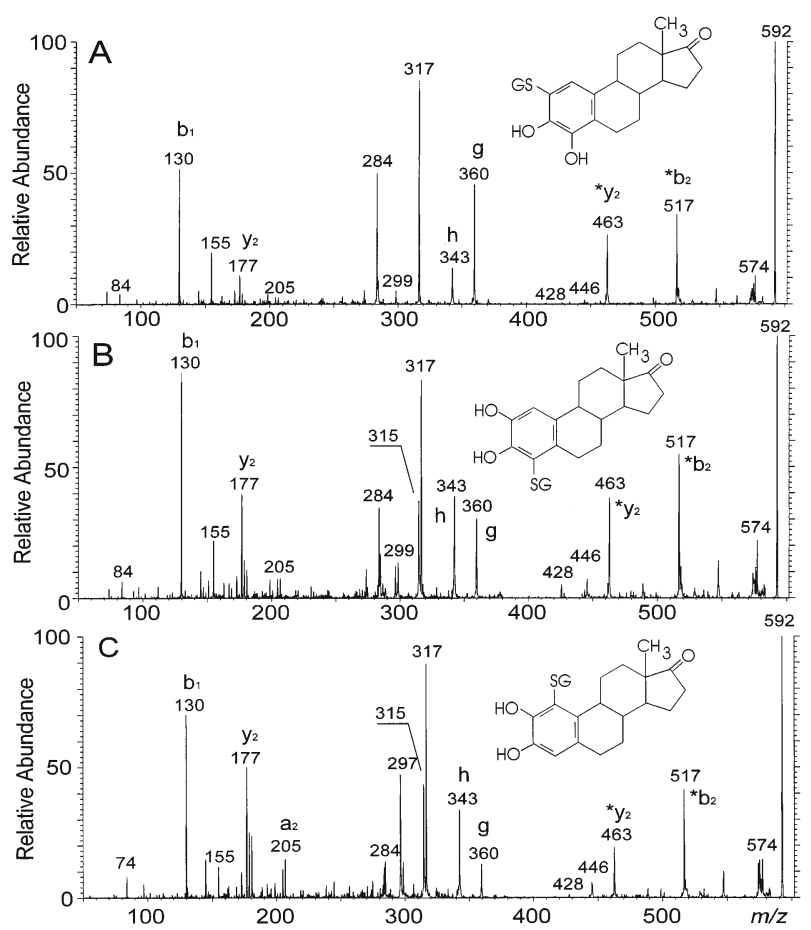

Figure 5. Tandem mass spectra of ESI-produced $[\mathrm{M}+\mathrm{H}]^{+}$ions from (A) 4-OHE 1 -2-SG, (B) 2-OHE 1 -4-SG, and (C) 2-OHE 1 -1-SG, obtained by using a tandem four-sector mass spectrometer.

conjugates also yields abundant $[\mathrm{M}+\mathrm{H}]^{+}$and some $[\mathrm{M}+\mathrm{Na}]^{+}$. Increasing the sampling cone potential by $135 \mathrm{~V}$ above the optimal value causes dissociation in the high-pressure region between the sampling cone and the skimmer, giving spectra (Figure 4) that are similar to those from the ion trap and the triple quadrupole except the isomerically distinctive $m / z 284$ and type- 4 ions are more apparent. The type- 4 fragments are barely detectable in the spectra of 4-OHE 1 -2-SG and 4-OHE $-2-\mathrm{SG}$, whereas for 2-OHE $-4-\mathrm{SG}$ and $2-\mathrm{OHE}_{2}-4-\mathrm{SG}$, they are quite abundant and even more abundant for $2-\mathrm{OHE}_{1}$ 1-SG and 2-OHE $-1-\mathrm{SG}$. Some key low-mass fragments, $\mathrm{b}_{1}, \mathrm{a}_{2}$, and $\mathrm{y}_{2}$ ions, are present in all spectra, but they are of low abundance. The unmodified $\mathrm{a}_{2}$ and $\mathrm{y}_{2}$ ions are presumably products of the corresponding modified species. Nevertheless, unambiguous assignments of the three $E_{1}$ and $E_{2}$ isomers are possible with the mass spectra from this method.

\section{High-Energy CAD Spectra}

The success in distinguishing isomers achieved by using ESI-source CAD provided additional incentive to test HE CAD for distinguishing the isomeric GSH adducts of $E_{1}$ and $E_{2}$. We chose to produce the precursor ions by both ESI and FAB.

ESI-produced ions. In contrast to LE-CAD spectra, abundant isomer-specific ions (type 4 and $\mathrm{m} / \mathrm{z} 284$ / 286) as well as types 1-3 fragment ions are observed in HE CAD spectra (Figure 5). The important distinguish- 

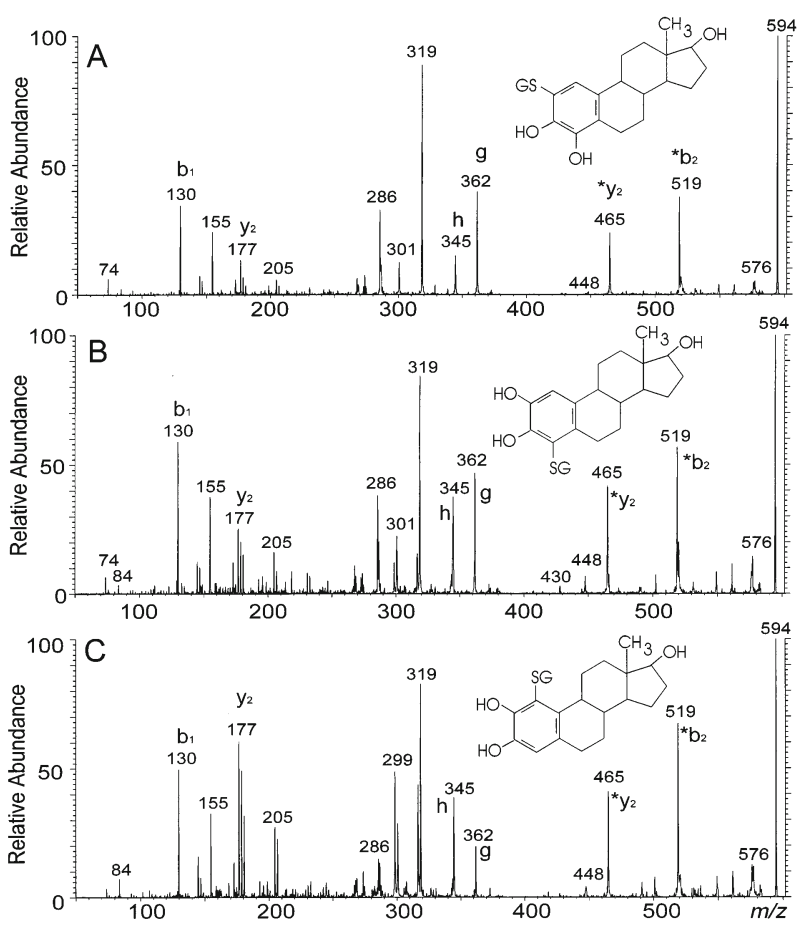

Figure 6. Tandem mass spectra of ESI-produced $[\mathrm{M}+\mathrm{H}]^{+}$ions from (A) 4-OHE $2-2-\mathrm{SG}$, (B) 2-OHE $-4-\mathrm{SG}$, and (C) 2-OHE $2-1-\mathrm{SG}$, obtained by using a tandem four-sector mass spectrometer.

ing features for 4-OHE $\mathrm{OH}_{1}-2-\mathrm{SG}$ with respect to the other isomers are the negligible abundances of the $\mathrm{m} / \mathrm{z} 315$ and 297 ions and the abundant $m / z 284$ ion. In the spectrum of $2-\mathrm{OHE}_{1}-4-\mathrm{SG}$, the $\mathrm{m} / z 315$ and 297 ions make their appearance at modest abundance. For the third isomer, 2-OHE $-1-\mathrm{SG}$, we see the highest abundances for the $m / z 315$ and 297 ions and the lowest abundances of the $m / z 284$ ion and the internal $g$ ion of $m / z 360$.

HE-CAD spectra from $E_{2}$ conjugates, shown in Figure 6 are similar to those of $E_{1}$ conjugates. All fragments containing the steroid are observed, but their masses are shifted by $2 \mathrm{u}$. Recalling that the key fragments for distinguishing the isomers are of type $4(\mathrm{~m} / z 317$ and 299), and the $m / z 286$ ion, we note that the ions of $m / z$ 317 and 299 are most abundant in the spectra of 2-OHE $-1-\mathrm{SG}$, not detectable in that of $4-\mathrm{OHE}_{2}-2-\mathrm{SG}$, and intermediate in that of the 2-OHE $-\mathrm{OH}_{2}-\mathrm{SG}$; this trend as the same as that for the $\mathrm{E}_{1}$ conjugates.

We propose as a mechanism for the type- 4 ions that oxidation of the steroid moiety occurs, involving transfer of a favorable tertiary hydrogen (Schemes I and IV) for $2-\mathrm{OHE}_{1}-1-\mathrm{SG}$ and $2-\mathrm{OHE}_{2}-1-\mathrm{SG}$. For $2-\mathrm{OHE}_{1}-4-\mathrm{SG}$ and $2-\mathrm{OHE}_{2}-4-\mathrm{SG}$ adducts, oxidation of the steroid moiety involves transfer of a secondary hydrogen (Scheme V), diminishing the abundances of the $m / z 315$ (from $\mathrm{E}_{1}$ ) and 317 (from $\mathrm{E}_{2}$ ) ions. With 4- $\mathrm{OHE}_{1}-2-\mathrm{SG}$ and $4-\mathrm{OHE}_{2}-2-\mathrm{SG}$ adducts, oxidation of the steroid is difficult because the sulfur attachment site is now more remote from the hydrogen sources. The proposed origin

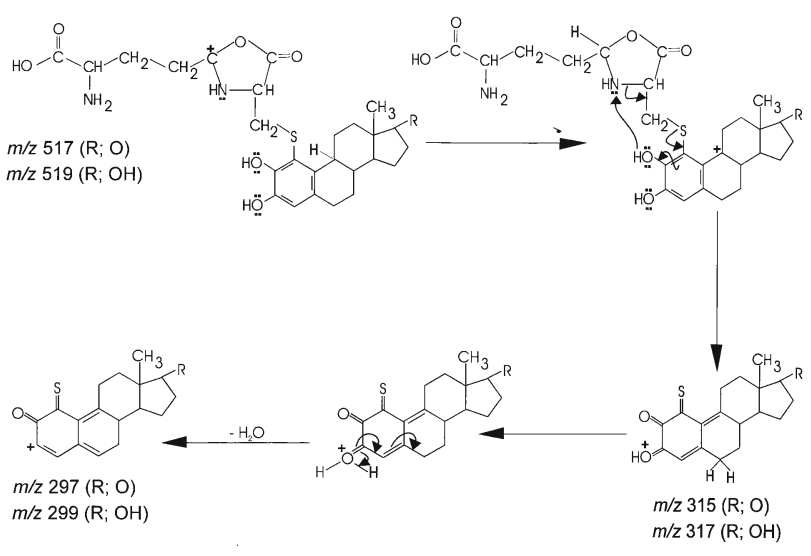

Scheme IV. Proposed mechanism for the formation of ion of $m / z 315\left(\mathrm{E}_{1}\right)$ and $317\left(\mathrm{E}_{2}\right)$ from 2-OHE-1-SG conjugates.

of the oxidized-steroid ion $\left[m / z 517\left(\mathrm{E}_{1}\right)\right.$ and $\left.519\left(\mathrm{E}_{2}\right)\right]$ is consistent with the breakdown curves (Figure 3 ).

FAB-produced ions. FAB-produced $[\mathrm{M}+\mathrm{H}]^{+}$ions of glutathione and of the isomeric conjugates were studied by using HE CAD to learn about the fragmentation of these ions under conditions in which the ions have higher internal energy [23]. Product ions from backbone fragmentation (type 1) become more pronounced because the proton can now attach to low proton-affinity amide nitrogens. This makes FAB in combination with $\mathrm{HE} C A D$, the method of choice for obtaining sequence information of peptides [24], although its sensitivity is not high.

The fragmentation behavior of the unmodified GSH, under high-energy conditions, is different from that observed under LE CAD conditions. The ion of $m / z 76$ $\left(\mathrm{y}_{1}\right), 84\left(\mathrm{a}_{1}-\mathrm{H}_{2} \mathrm{O}\right), 179\left(\mathrm{y}_{2}\right)$ and $130\left(\mathrm{~b}_{1}\right)$ are more abundant upon high-energy collisions. The $\mathrm{z}_{2}$ (of $\mathrm{m} / \mathrm{z}$ 162) and $\mathrm{b}_{2}$ (of $m / z$ 233) are less abundant than upon low-energy activation. The HE CAD spectrum of ESIproduced ions is similar to that of FAB-produced ions.

$\mathrm{HE} C A D$ spectra of FAB-produced $\mathrm{E}_{1}$ and $\mathrm{E}_{2}$-conju-

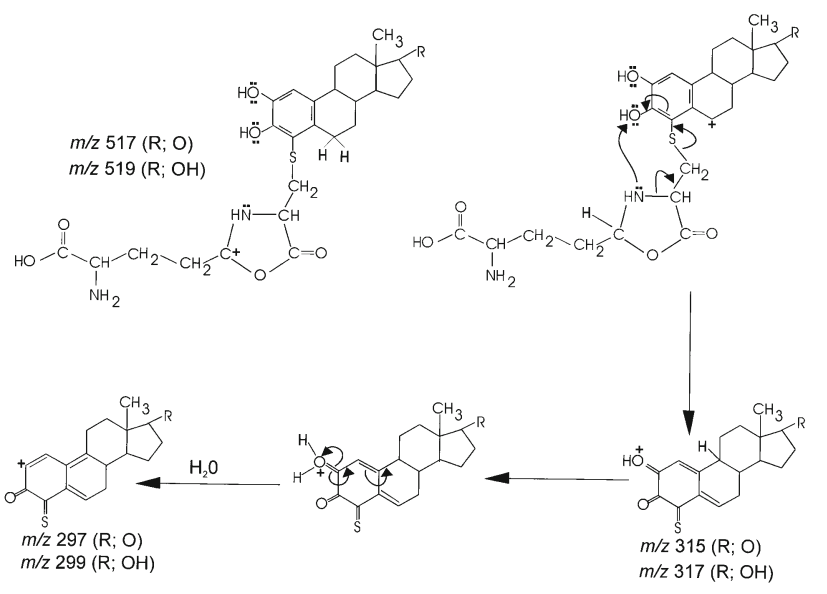

Scheme V. Proposed mechanism for the formation of ion of $\mathrm{m} / \mathrm{z}$ $315\left(E_{1}\right)$ and $317\left(E_{2}\right)$ from 2-OHE-4-SG conjugates. 
gate ions show clearly the trend established for ESIproduced ions: the $m / z 315$ (from $E_{1}$ ) and 317 (from $E_{2}$ ) ions and the water-loss products at $m / z 297$ and 299 are absent, modest, and high abundance in the spectra of 4-OHE-2-SG, 2-OHE-4-SG, and 2-OHE-1-SG, respectively. In addition, the low-mass region of the spectra shows that more abundant backbone-cleavage (type 1) product ions are formed.

\section{Metastable-Ion Spectra}

Ions with relatively higher internal energy than the stable ions fragment during transit to the detector and give metastable-ion spectra. Similar to the breakdown graphs obtained using the triple quadrupole, MI spectra give information on the lowest energy fragments, which are usually first- and second-generation product ions. The ions are less abundant than in CAD spectra, explaining the need for a magnification factor of 10 or 20 times greater than that used for CAD spectra.

A typical MI spectrum contains, as the most abundant product ion, that of $m / z 463$, which is a * $\mathrm{y}_{2}$ ion formed from the $[\mathrm{M}+\mathrm{H}]^{+}$ions, showing that this firstgeneration ion is formed by the lowest energy process. Other fragment ions at $m / z 575\left(\left[\mathrm{M}+\mathrm{H}-\mathrm{NH}_{3}\right]^{+}\right), 574$ $\left(\left[\mathrm{M}+\mathrm{H}-\mathrm{H}_{2} \mathrm{O}\right]^{+}\right), 173\left(\mathrm{~d}_{2}\right)$, and $130\left(\mathrm{~b}_{1}\right)$ have relative abundances between 5\% and 30\%. These MI spectra have little utility for structure determination.

\section{Conclusions}

A long-standing goal of our research has been to develop an understanding of the fragmentation chemistry of carcinogen-DNA adducts to assist tumor-initiation studies. Isomer distinction is important in reaching our goal because some isomeric adducts depurinate, some produce lesions, and others are harmless. Detecting DNA modifications to estimate risk is difficult because levels of modification are small. Therefore, we are expanding our research to GSH conjugates, which, when bound to estrogens, may be particularly important for estimating risk for breast cancer.

Unambiguous identification of the spectra relies on the type- 4 ions of $m / z 315$ and 297 for $E_{1}$ conjugates and of $m / z 317$ and 299 for $E_{2}$ conjugates. The formation of these ions is most favored when the GSH attachment is at position 1 of the steroid, but still occurs when the attachment is at position 4 . We picture these unusual isomerically distinctive reactions as proceeding by oxidation of the steroid moiety and reduction of the departing neutral GSH. These trends are more obvious in HE CAD and in ESI-source CAD spectra than in the LE CAD spectra from ion-trap and triple-quadrupole tandem instruments, although higher order MS/MS experiments with the ion trap may produce the desired information. Increasing the collision energy in the lowenergy regime increases the relative abundances of these ions at the expense of high-mass ions. LE CAD requires a tradeoff when choosing the collision energy, and an uninformed choice without a reference compound may give incomplete information.

\section{Acknowledgments}

This research was supported by the National Institutes of Health (NIH) (grant no. P01CA49210) and by the NIH National Center for Research Resources (grant no. P41RR00954).

\section{References}

1. Ball, P.; Knuppen, R. Acta Endocrinol (Copenhagen) 1980, 93 (Suppl. 232), 1-127.

2. Martucci, C. P.; Fishman, J. Pharmac. Ther. 1993, 57, 237-257.

3. Dwivedy, I.; Devanesan, P.; Cremonesi, P.; Rogan, E.; Cavalieri, E. Chem. Res. Toxicol. 1992, 5, 828-833.

4. Stack, D. E.; Byun, J.; Gross, M. L.; Rogan, E. G.; Cavalieri, E. L. Chem. Res. Toxicol. 1996, 9, 851-859.

5. Cavalieri, E. L.; Stack, D. E.; Devanesan, P. D.; Todorovic, R.; Dwivedy, I.; Higginbotham, S.; Patil, K. D.; Gross, M. L.; Gooden, J. K.; Ramanathan, R.; Cerny, R. L.; Rogan, E. G. Proc. Natl. Acad. Sci. USA 1997, 94, 10937-10942.

6. Boyland, E.; Chasseand, L. F. Adv. Emzymol. 1969, 32, 173-219.

7. Meister, A.; Anderson, M. E. Annu. Rev. Biochem. 1983, 52, 711-760.

8. Cheesman, B. V.; Arnold, A. P.; Rabenstein, D. L. J. Am. Chem. Soc. 1988, 110, 6359-6364.

9. Meister, A. In Glutathione Chemical Biochemical and Medical Aspects; Dolphin, D.; Avramovic, O.; Poulson, R., Eds.; Wiley: New York, 1988; pp 1-48.

10. Armstrong, R. N. Chem. Res. Toxicol. 1991, 4, 131-140.

11. Haroldsen, P. E.; Reilly, M. H.; Hughes, H.; Gaskell, S. J.; Porter, C. J. Biomed. Environ. Mass Spectrom. 1988, 15, 615-621.

12. Fenselau, C.; Smith, P. B. W. Xenobiotica 1992, 22, 1207-1219.

13. Parker, C. E.; de Wit, J. S. M.; Smith, R. W.; Gopinathan, C. H.; Sanders, J. M.; Bend, J. R. Biomed. Environ. Mass Spectrom. 1988, $15,623-634$.

14. Robertson, I. G. C.; Palmer, B. D.; Shaw, J. G. Biolog. Mass Spectrom. 1993, 22, 661-665.

15. (a) Ballard, K. D.; Raftery, M. J.; Jaeschke, H.; Gaskell, S. J. J. Am. Soc. Mass Spectrom. 1991, 2, 55-68; (b) Davis, M. R.; Baillie, T. A. J. Mass Spectrom. 1995, 30, 57-68.

16. Ramanathan, R.; Cao, K.; Stack, D.; Cavalieri, E.; Gross, M. L. Proceedings of the 45th ASMS Conference on Mass Spectrometry and Allied Topics, Palm Springs, CA, June 1-5, 1997; p 9.

17. Cao, K.; Stack, D. E.; Ramanathan, R.; Gross, M. L.; Rogan, E. G.; Cavalieri, E. L., Chem. Res. Toxicol., in press.

18. Gross, M. L. Tandem mass spectrometry: Multisector magnetic instruments. In Methods in Enzymology, Vol 193, Mass Spectrometry; McCloskey, J. A.; Ed., Academic: San Diego, 1990; pp 131-153.

19. Roepstorff, P.; Fohlman, J. Biomed. Environ. Mass Spectrom. 1984, 11, 601; Sato, K.; Asada, T.; Ishihara, M.; Kunihiro, F.; Kammei, Y.; Kubota, E.; Costello, C. E.; Martin, S. A.; Scoble, H. A.; Biemann, K. Anal. Chem. 1987, 59, 1652-1659.

20. Haroldsen, P. E.; Reilly, M. H.; Hughes, H.; Gaskell, S. J.; Porter, C. J. Biomed. Environ. Mass Spectrom. 1988, 15, 615-621.

21. Van Amsterdam, M. W.; Ingemann, S.; Nibbering, N. M. M. J. Mass Spectrom. 1995, 30, 43-51.

22. Tang, W.; Abbott, F. S. Chem. Res. Toxicol. 1996, 9, 517-526.

23. Jones, J. L.; Dongre, A. R.; Somogyi, A.; Wysocki, V. H. J. Am. Chem. Soc. 1994, 116, 8368-8369.

24. Gaskell, S. J. J. Protein Chem. 1994, 13, 494-501. 